\title{
Valproate for treatment of chronic central pain after spinal cord injury. A double-blind cross-over study
}

\author{
A M Drewes MD, A Andreasen MD, L H Poulsen MD \\ Spinal Cord Injury Centre, Department of Rheumatology, Viborg County Hospital, \\ DK-8800 Viborg, Denmark.
}

Chronic central pain is a frequent complication after spinal cord injury. Anticonvulsant drugs, among them valproate, have been recommended for treatment. In this paper we conducted a double-blind, cross-over study comparing valproate and placebo for severe chronic central pain. During the study, serum concentration of valproate, pain and side effects were registered and the dose was adjusted according to these. No significant analgesic effects of valproate could be demonstrated although serum concentration and dose reached a high level. Few studies of pain following spinal cord injury exist and we recommend that further studies be performed.

Keywords: spinal cord injury; central pain; valproate.

\section{Introduction}

Intractable pain is a frequent sequel after spinal cord injury (SCI). The incidence of chronic pain following SCI ranges from 6 to $94 \%$ according to various authors. ${ }^{1-4}$ Correspondingly, in a previous study we found frequent pain reported by $66 \%$ of the patients. ${ }^{5}$ According to most authors ${ }^{2.6}$ painful sensations after SCI are divided into (1) root pain, (2) visceral pain and (3) central pain or phantom body pain. Central pain felt below the level of the lesion is the commonest form and treatment is very difficult. Surgical treatment is of limited value, ${ }^{6,7}$ and conventional analgesics have not been of much assistance. Antiepileptic medications such as carbamazepine have been recommended, ${ }^{7}$ and during the last years sodium valproate has been used for the treatment of central pain with good results in some patients. The aim of this study was to conduct a double-blind, placebo controlled study of valproate for the treatment of chronic central pain following SCI.

\section{Methods}

The study was performed from August 1990 to May 1991. All potential subjects were either hospitalised or were outpatients at the spinal cord injury centre who had a complaint of pain and were referred to one of the physicians, who performed a preliminary telephone screening evaluation. Patients who met the study criteria were invited to participate in the research project. A total of 20 patients agreed to do so: they were all outpatients except three, who were hospitalised in the spinal cord injury centre for some of the weeks during treatment.

Included were patients older than 18 years with nonprogressive SCI and central pain lasting for more than 1 month. All patients had failed to respond to conventional treatments. Central pain was defined as pain distal to the level of injury in an area with loss of normal feeling., ${ }^{2,7}$ Excluded were patients with severe obesity or liver disease, pregnant women, patients treated with anticoagulant drugs, phenobarbital or primidone, and patients with known intolerance to valproate.

The study was a double-blind, cross-over study with the first treatment period of 3 weeks with valproate or placebo followed by a 'wash-out' period of 2 weeks and a new 3 week treatment period (Fig 1). Patients were interviewed and had 1 hour's instruction at baseline by one of the authors 


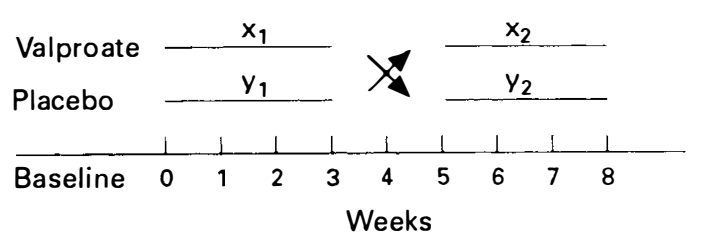

Figure 1 The cross-over design.

(AMD) who undertook the further adjustment of medicine during the treatment. Weekly telephone assessments and contact to the patients were performed by the other two authors, who did not know which treatment the patients had received. A written report of the patient's current pain status on a 1-5 verbal scale, side effects and consumption of medicine was delivered to AMD after each telephone assessment (Fig 2). Thereby the double-blind procedure was confirmed. Every week serum concentration of valproate and liver function tests were done and the medicine was adjusted by AMD according to the following procedure (Fig 2).

Following randomisation patients began treatment with $600 \mathrm{mg}$ valproate or a corresponding placebo tablet b.i.d. If patients had consumption of other analgesics, the dose was kept constant during the study. Laboratory examinations and telephone assessments were made after 5 days. If the patient still had pain, if no side effects had occurred and if the serum concentration was less than $650 \mu \mathrm{mol} / \mathrm{l}$, the daily dose was individually increased depending on the serum concentration, body weight and cur- rent pain status. The patient was informed in a letter. The same procedure was repeated after 12 days of treatment. Patients treated with placebo and laboratory examinations had a similar increase in their tablets, so that the patients could not distinguish between the two treatment regimes. The Danish version of the McGill Pain Questionnaire (MPQ) was completed before and after each treatment series. A high correlation has been demonstrated between the Danish and the English descriptors of the MPQ. ${ }^{8}$ As in the original MPQ four types of measures were obtained:

1 The Pain Rating Index (PRI) based upon the rank values of the words selected from the 20 subclasses of pain descriptors. According to Deschamps et $a l^{9}$ the rank values within the subclasses were adjusted to fall between 0 and 1 (or $0-100 \%$ ) when the PRIs were calculated. The scores were divided into sensory (PRI-S), affective (PRI-A), evaluate (PRI-E) and miscellaneous (PRI-M) dimensions of pain.

2 The Number of Words Chosen (NWC) from the list.

3 The Present Pain Intensity (PPI) on a 1-5 verbal scale.

4 A drawing of the pain localisation on a figure of the body (area in per cent of total body area).

\section{Statistics}

Nonparametric methods were used for the statistical analysis. As in every cross-over

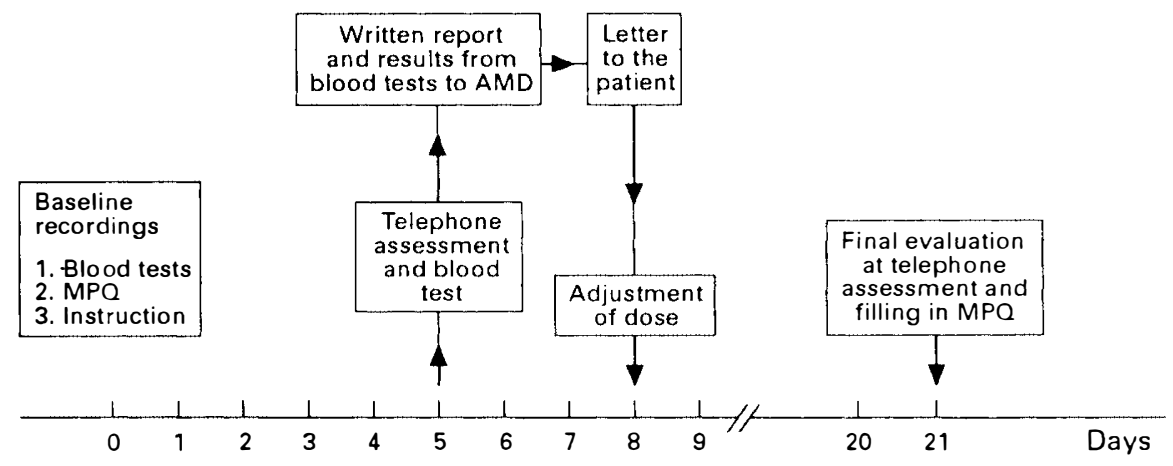

Figure 2 Flow chart demonstrating the evaluation procedure and adjustments of medicine. The procedure for days 5-8 was repeated for days $12-15$. 
design there is a risk of a 'carry-over' effect as well as 'regression towards the mean'. The Mann-Whitney test was used for analysing carry-over effects comparing the effect of treatment in period $x_{1}+y_{2}$ and $\mathrm{y}_{1}+\mathrm{x}_{2}$ in the two series (Fig 1). The same test was used for analysing regression towards the mean comparing the effect in period $x_{1}-y_{2}$ and $x_{2}-y_{1} \cdot{ }^{10}$ Treatment effect was analysed using the Wilcoxon matched-pair rank test or Pratt's test with difference scores of zero.

\section{Results}

All 20 patients, 15 males and five females, completed the study. Sixteen were paraplegic and four tetraplegic. One patient had SCI due to spinal stenosis, the others all had a traumatic cause. Median age was 32.5 years (18-75) and median time after SCI was 79.5 months (4-122). One patient filled in the MPQ wrongly in the valproate period and these data were omitted from the statistical analysis. Pain started a few months after SCI in all of the patients, and they had all tried various other forms of analgesics without benefit. All pain sensations were distal to the level of the lesion. The words describing pain most frequently chosen from the baseline MPQ were tingling $(55 \%)$, shooting $(50 \%)$, agonising $(45 \%)$, cutting and cruel $(40 \%)$. One patient had only 2 weeks of valproate treatment (daily dose was $1800 \mathrm{mg}$ and serum concentration was $748 \mu \mathrm{mol} / 1$ ) as gastroenteritis occurred; liver function tests were normal, and retrospectively we do not believe that the gastroenteritis was a side effect. Four patients in the valproate series had side effects (dizziness), and the dose was not increased further. None of the patients in the placebo series had side effects. All laboratory examinations were normal.

In the statistical analysis no evidence of carry-over effect or regression towards the mean was observed, indicating that the study design was acceptable. After 3 weeks of treatment six patients in the valproate series improved and two had worsening of the pain. In the placebo series four patients improved and one was worse. The median dose of valproate was $1800 \mathrm{mg}(600-2400)$ and median . serum concentration was $614 \mu \mathrm{mol} / 1$ (128-999). The results from the telephone assessments and the MPQ subscores are given in Table I. No significant differences were observed comparing patients in the valproate and placebo series, although a trend towards improvement was observed in most subgroups during valproate treatment.

\section{Discussion}

Chronic central pain is a frequent complication following SCI. Various authors have recommended anticonvulsant drugs ${ }^{7,11}$ for its treatment. This is in accordance with the belief that central pain is a variety of deafferentation pain, similar to the pain seen in patients with peripheral nerve, thalamic and parietal lobe lesions. ${ }^{12}$ There is convincing evidence that the deafferentation produces abnormal physiological activity in spinal and brain cells deprived of normal sensory input, and these cells fire spontaneously. ${ }^{6,13}$ Thus anticonvulsivant drugs are a rational pharmacological approach. Moreover, valproate has GABAergic mechanisms within the $\mathrm{CNS},{ }^{14}$ and several studies both in animals and in humans have provided evidence for a link between GABA-ergic mechanisms and the

Table I Mean improvement in telephone assessments and MPQ subscores comparing baseline scoring to scores after 3 weeks of treatment

\begin{tabular}{|c|c|c|c|c|c|c|c|c|}
\hline Series & $\begin{array}{l}\text { Patients } \\
\text { improved }\end{array}$ & PPI & $\begin{array}{c}\text { Area } \\
\%\end{array}$ & $\begin{array}{c}\text { PRI-S } \\
\%\end{array}$ & $\begin{array}{c}\text { PRI-A } \\
\%\end{array}$ & $\begin{array}{c}\text { PRI-E } \\
\%\end{array}$ & $\underset{\%}{\text { PRI-M }}$ & $\begin{array}{c}\text { PRI-T } \\
\%\end{array}$ \\
\hline Valproate & 6 & 0.2 & 2.1 & 0.5 & 0.4 & 8.4 & 2.1 & 1.6 \\
\hline Placebo & 4 & -0.1 & 0.2 & -2.7 & 0.2 & -2.0 & 0.1 & -1.7 \\
\hline
\end{tabular}

For abbreviations, see text. 
opioid system. However, few studies have been conducted to demonstrate the analgesic effects of valproate ${ }^{15-17}$ and to the authors' knowledge no studies of the use of anticonvulsive drugs for pain following SCI exist.

In this study we could not demonstrate significant analgesic effects of valproate. The study group had severe tingling, shooting and cutting pain below the level of injury with pain onset a few months after SCI, which is typical for central pain. ${ }^{2,18}$ The pain was severe and constant, and several analgesics were tried without benefit, confirming that the management of pain in this patient group should be considered to be difficult. The dose of valproate was considered sufficient for effect as serum concentrations reached the upper limit during the last treatment week in most patients; thus a beneficial effect should be expected. Thirtythree per cent improved during valproate treatment, but no statistically significant effect was observed compared to the placebo series. In any event, four patients wished to continue with valproate therapy after the study, and some patients might benefit from the treatment, although our results could not demonstrate a significant effect. The risk of a type II error must be considered when the number of patients is taken into account, but to eliminate this risk at least 150 patients would require to be included, which is not realistic.

In the treatment of chronic central pain after SCI, anticonvulsant drugs, ${ }^{7,11,17}$ antidepressants $^{19,20}$ and transcutaneous nerve stimulation $^{7,21}$ have been recommended. Moreover, a recent study ${ }^{22}$ reported successful treatment with amitriptyline and carbamazepine, and drug combinations may be of value in some patients. There is, however, agreement that the presently available pharmacological agents for pain management are most effective in patients with mild or moderate pain. In general, valproate cannot be recommended for severe central pain. Few studies of pain following SCI exist, although the disorder is very common, and we recommend that further studies with larger groups of patients be performed.

\section{Acknowledgement}

This study was supported by Rhône-Poulenc Rorer A/S.

\section{References}

1 Munro D (1948) Rehabilitation of veterans paralysed as the result of injury of the spinal cord and cauda-equina injuries. Am J Surg 75: 3-17.

2 Burke DC (1973) Pain in paraplegia. Paraplegia 10: 297-313.

3 Davis L, Martin J (1947) Studies upon spinal cord injuries. II. The nature and treatment of pain. J Neurosurg 4: 483-491.

4 Botterell EH, Callahan JC, Jousse AT (1954) Pain in paraplegia. Clinical management and surgical treatment. Proc R Soc Med 47: 281-288.

5 Drewes AM, Andreasen A, Olsson AT, Slot O (1989) Sygdomsforløbet hos patienter indlagt i en rehabiliteringsafdeling efter rygmarvslæsion. Ugeskrift for lager 151: 3233-3236. (Summary in English).

6 Melzack R, Loeser JD (1978) Phantom body pain in paraplegics: Evidence for a central pattern generating mechanism' for pain. Pain 4: 195-210.

7 Davis R (1975) Pain and suffering following spinal cord injury. Clin Orthop 112: 76-80.

8 Drewes AM, Helweg-Larsen S, Petersen P et al (1993) McGill Pain Questionnaire translated into Danish: Experimental and clinical findings. Clin J Pain 9: 80-87.

9 Deschamps M, Band PR, Coldman AJ (1988) Assessment of adult cancer pain. Pain 32: 133-139.

10 Woolsey RM (1986) Chronic pain following spinal cord injury. J Am Paraplegia Soc 9: 39-41.

11 Hills M, Armitage P (1979) The two-period cross-over clinical trial. J Clin Pharmacol 8: 7-20.

12 Pagni CA (1984) Central pain due to spinal cord and brain stem damage. In: Wall PD, Melzack R, editors. Textbook of Pain. Churchill Livingston, New York: 481-495.

13 Lenz FA, Tasker RR, Dostrovsky JO et al (1987) Abnormal single-unit activity recorded in the somatosensory thalamus of a quadriplegic patient with central pain. Pain 31: 225-236.

14 Gram L (1988) Experimental studies and controlled clinical testing of valproate and vigabatrin. Acta Neurol Scand 78: 241-270.

15 Auff E, Holzner F, Wessely P (1985) Weitere Therapie-möglichkeiten mit Valproinsäure (Convulex). Wiener Medizinischer Wochenschrift 135: 421-423. (Summary in English).

16 Sørensen KV (1988) Valproate: A new drug in migraine prophylaxis. Acta Neurol Scand 78: 346-348. 
17 Balazy TE (1992) Clinical management of chronic pain in spinal cord injury. Clin J Pain 8: 102-110.

18 Frisbie JH, Aguilera EJ (1990) Chronic pain after spinal cord injury: An expedient diagnostic approach. Paraplegia 28: 460-465.

19 Donovan WH, Dimitrijevic MR, Dahm L et al (1982) Neurophysiological approaches to chronic pain following spinal cord injury. Paraplegia 20: 135-146.

20 Maury M (1978) About pain and its treatment in paraplegics. Paraplegia 15: 349-352.

21 Hachen HJ (1978) Psychological, neurophysiological and therapeutic aspects of chronic pain: Preliminary results with transcutaneous electrical stimulation. Paraplegia 15: 353-367.

22 Sandford PR, Lindblom LB, Haddox JD (1992) Amitriptyline and carbamazepine in the treatment of dysesthetic pain in spinal cord injury. Arch Phys Med Rehabil 73: 300-301. 